\title{
9. SEISMIC STUDIES OF METHANE GAS HYDRATE, OFFSHORE VANCOUVER ISLAND ${ }^{1}$
}

\author{
G.D. Spence, ${ }^{2}$ T.A. Minshull, ${ }^{3}$ and C. Fink ${ }^{2}$
}

\begin{abstract}
A seismic program in June 1993 on the continental slope off Vancouver Island focused on the bottom simulating reflector (BSR) formed at the base of a methane hydrate layer. Wide-angle ocean bottom seismometer (OBS) data and single-channel seismic data were collected in the vicinity of Hole 889B of the Ocean Drilling Program.

Near-vertical to wide-angle arrivals from a 120 -in. ${ }^{3}$ air gun were recorded during two deployments of five OBSs. A strong BSR was observed to offsets of about $3.6 \mathrm{~km}$. Traveltime inversions were conducted for arrivals at four OBS sites, and the results show that the average velocity above the BSR is about $1.70-1.78 \mathrm{~km} / \mathrm{s}$ in the $90( \pm 30) \mathrm{m}$ interval above the BSR. Ray tracing constrained the vertical velocity gradient to about $1.0 \mathrm{~km} / \mathrm{s} / \mathrm{km}$. Velocities above the BSR were considered higher than those of unhydrated sediments at equivalent depths, and provided estimates for hydrate saturations of $11 \%-20 \%$ above the BSR.

Approximately $1050 \mathrm{~km}$ of single-channel seismic data were digitally recorded from the 120 -in. ${ }^{3}$ air gun, plus $110 \mathrm{~km}$ recorded from a 40 -in. ${ }^{3}$ air gun. A grid of lines was acquired with the larger gun, at a nominal line spacing of $200 \mathrm{~m}$. A map of BSR reflection amplitudes over this grid indicates the detailed variation in hydrate or free-gas distribution in the region of the drill hole. A major control on their distribution appears to be topography, with the strongest BSR occurring beneath a ridge formed by an anticlinal uplift of accretionary wedge sediments.

The BSR response for different air gun sizes, including a large air gun array recorded during a previous multichannel survey, was compared along coincident lines. With increasing source frequency, the BSR continuity became poorer and reflection coefficients became smaller; as well, only a single BSR reflection was observed on all seismic sections. A thin layer with large hydrate or free-gas concentrations, a few meters in thickness, is thus unlikely to be present at the BSR. The different sources, which have different lateral resolutions or Fresnel zone widths, also indicate that hydrate may be discontinuous laterally at a scale of $200-400 \mathrm{~m}$.
\end{abstract}

\section{INTRODUCTION}

Marine gas hydrates are substances consisting of rigid water molecule cages stabilized by enclosed gas molecules, notably methane (Sloan, 1990). The pressure-temperature stability field of methane hydrate (Englezos and Bishnoi, 1988) indicates that it is stable at conditions found in oceanic sediments at depths of a few hundred meters below the seafloor, where water depths exceed about $300 \mathrm{~m}$. The hydrate is generally considered to form almost entirely from bacterially generated methane, although in a few cases (e.g., Gulf of Mexico and offshore Guatemala) the hydrate gas signatures may be consistent with a thermogenic origin for the methane (Kvenvolden et al., 1984). Methane hydrates are considered significant because they are estimated to form the largest reservoir type of natural gas (Kvenvolden, 1993; MacDonald, 1990). As a consequence, they have the potential for a major clean hydrocarbon source. Release of methane from this large reservoir could also have a significant impact on atmospheric composition and global climate.

The detection of hydrates beneath the deep seafloor is primarily through a strong bottom-simulating reflector (BSR), which parallels the seafloor and commonly cuts across stratigraphy. The BSR is thought to mark the base of the hydrate stability field, because this is controlled largely by subseafloor isotherms that approximately paral-

'Carson, B., Westbrook, G.K., Musgrave, R.J., and Suess, E. (Eds.), 1995. Proc. ODP, Sci. Results, 146 (Pt. 1): College Station, TX (Ocean Drilling Program).

${ }^{2}$ School of Earth and Ocean Sciences, University of Victoria, Victoria, British Columbia, Canada V8W 2 Y 2.

'Bullard Laboratories, Department of Earth Sciences, University of Cambridge, Cambridge, United Kingdom CB3 0EZ. lel the seafloor. The BSR exhibits reversed polarity and thus a negative impedance contrast produces the reflection, but an important unresolved question is whether the contrast is due mainly to high-velocity hydrated sediments above the BSR or to low-velocity gas-saturated sediments below the BSR. Velocities higher than normal have been interpreted on several margins, with hydrate thicknesses less than about $50 \mathrm{~m}$, for example, Blake Ridge (Wood and Stoffa, 1994), Makran (Minshull and White, 1989), Colombia (Minshull et al., 1994), and Cascadia (Hyndman and Spence, 1992). Gas-saturated sediments, usually less than about $30 \mathrm{~m}$ in thickness, have also been inferred at many of these and other locations (e.g., Peru [Miller et al., 1991], Blake Ridge [Katzman et al., 1994]).

On the Cascadia Margin, extensive multichannel seismic data were collected as part of the site surveys for the Ocean Drilling Program (ODP) Leg 146 drilling program. The data helped provide information on the regional framework of the accretionary prism (Hyndman et al., 1994), and detailed seismic analyses on the BSR helped constrain the velocity distribution near the hydrate. Forward modelling of the amplitude variation with offset was carried out by Hyndman and Spence (1992). Their preferred (but non-unique) model contained high velocities above the BSR; furthermore, the amplitudes were not consistent with a gas layer in which Poisson's ratios were very low (i.e., $0.1-0.2$, corresponding to $P$-wave velocities $<1.3$ $\mathrm{km} / \mathrm{s}$ ), which are values predicted from laboratory data and theoretical studies for gas concentrations greater than a few percent (Murphy, 1984; Domenico, 1976). However, a small reduction in Poisson's ratio (e.g., to 0.3 , with $P$-wave velocities of $\sim 1.5 \mathrm{~km} / \mathrm{s}$ ), consistent with a small quantity of free gas, could not be excluded. Singh et al. (1993) and Singh and Minshull (1994) applied a full-waveform inversion technique to the multichannel data near Hole 889 , and interpreted a 
30-m-thick low-velocity layer below the BSR with $P$-wave velocity of $1.4-1.58 \mathrm{~km} / \mathrm{s}$ and Poisson's ratio of $0.32-0.37$. This was consistent with the Leg 146 drilling results, where downhole velocity logging and vertical seismic profiling found velocities below the BSR of $1.5 \mathrm{~km} / \mathrm{s}$ or less (MacKay et al., 1994). However, on all the BSR velocity determinations, there have been few direct constraints on what constitutes "normal" velocities, and so there is large uncertainty in the reference velocity profile that controls the quantitative estimates of the amount of hydrate or gas saturation.

In this article we present preliminary results from a single-channel vertical incidence survey and a wide-angle seismic study of ocean bottom seismometer data recorded in the region of Hole 889 on the Cascadia Margin. The objectives are to determine the detailed lateral distribution of hydrate around the drill hole and to constrain the vertical velocity distribution above and below the BSR. Several types of analysis were undertaken in this study: (1) traveltime inversion/ray tracing of wide-angle arrivals recorded on multiple ocean bottom seismometers (OBSs) to determine average velocities and maximum vertical velocity gradients; (2) calculation of vertical incidence reflection coefficients over a detailed grid of single-channel seismic (SCS) lines to map lateral variations in BSR reflection strength and continuity; and (3) comparison of the BSR response along several lines shot repeatedly with various sizes of air gun sources to determine if the frequency dependent character can be used to resolve vertical and lateral velocity variations.

\section{DATA ACQUISITION}

The seismic data were collected in June 1993 on the John P. Tully, in a collaborative experiment between the University of Victoria and the University of Cambridge. The area of study was on the continental slope off Vancouver Island (Fig. 1), in the region of Hole 889B drilled by ODP in October 1992. A total of $\sim 1160 \mathrm{~km}$ of SCS data was recorded digitally. Of this total, $1050 \mathrm{~km}$ were acquired using a 120 -in. ${ }^{3}$ air gun fired at an interval of $14 \mathrm{~s}(\sim 35 \mathrm{~m})$, whereas $110 \mathrm{~km}$ were recorded with a 40 -in. ${ }^{3}$ source fired at a $10 \mathrm{~s}(\sim 25 \mathrm{~m})$ interval. Dominant frequencies were $60-90 \mathrm{~Hz}$ for the larger gun and $150-200$ $\mathrm{Hz}$ for the smaller gun. In this paper we present results mainly from a $12-\mathrm{km}$ by $9-\mathrm{km}$ grid of 47 lines, acquired with the 120 -in. ${ }^{3}$ air gun, in which the nominal line separation was $200 \mathrm{~m}$ (Fig. 2A). We also collected another grid of 28 lines, $3.3 \mathrm{~km}$ in length and separated by $100 \mathrm{~m}$, using the 40 -in. ${ }^{3}$ air gun; one of these lines, which passes near the drill site location, is presented.

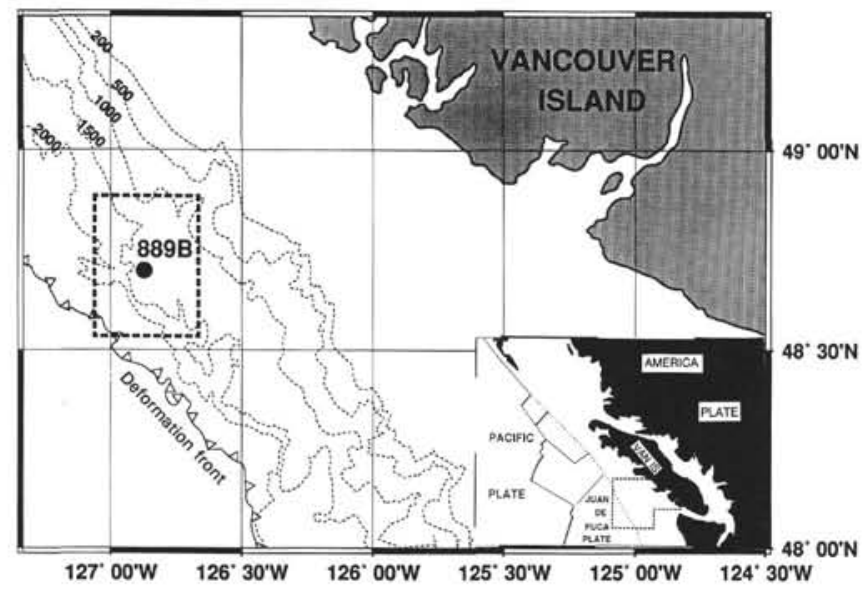

Figure 1. Location map showing the region on the Vancouver Island continental slope where the combined wide-angle and single-channel seismic survey was conducted. The box marks the area of Figure $2 \mathrm{~B}$, and includes Hole 889B. Bathymetry is in meters.
Wide-angle data from the 120 -in. ${ }^{3}$ air gun were collected on a set of five digital OBSs from the University of Cambridge. In deployment $\mathrm{A}$, the instruments were placed in a grid at a spacing of $3.3 \mathrm{~km}$. The location of lines recorded out to a shot-receiver offset of about $10 \mathrm{~km}$ are shown in Figure 2B. In deployment B, with an OBS grid spacing of $1 \mathrm{~km}$, the air gun was fired on 16 lines out to offsets of 5$6 \mathrm{~km}$.

\section{DATA CHARACTERISTICS}

Examples of SCS lines are shown in Figures 3 and 4, together with coincident multichannel lines recorded in 1989. The source for the multichannel data was a tuned air gun array of 30 elements of total volume 7820 in. ${ }^{3}$ Processing has been discussed by Spence et al. (1991) and Hyndman et al. (1994); it included exponential gain and spherical divergence corrections, source wavelet deconvolution, and $\mathrm{f}-\mathrm{k}$ demultiple application. Additional processing by T. Yuan at the University of Victoria focused on detailed velocity analyses, dipmoveout processing, and finite difference migration. Very little processing was required for the single-channel data. Although the single gun produced strong bubble pulses $\left(100 \mathrm{~ms}\right.$ period for the 120 -in. ${ }^{3}$ source; $75 \mathrm{~ms}$ for the 40 -in. ${ }^{3}$ source), simple predictive deconvolution worked very well in removing these bubble pulses.

Lines $89-08$ and 2 A (Fig. 3) were run perpendicular to the continental margin and across Leg 146 Site 889 . The drill site was located in a region of a strong and continuous BSR, as seen on both the multichannel and single-channel sections. However, the BSR appears less continuous on the SCS data, especially near the region where Line 89-08 intersects Line 89-10 (Fig. 3). This trend is even more prominent for SCS-6, which is coincident with $89-10$ (Fig. 4). Certainly, some of the variability on the SCS sections represents a real variation in the strength of the BSR, since the signal is strong enough to rise above the noise level in some areas but not in others. However, two additional factors may contribute to the apparent greater continuity on the MCS sections: (1) the observed amplitudes for the BSR commonly increase with source-receiver offset, particularly at offsets greater than $\sim 3 \mathrm{~km}$ (Hyndman and Spence, 1992), and the stacked MCS data include these larger amplitudes, and (2) with the greater signal strength for the MCS data, variations in amplitude are not easily seen with the variable-area display on the sections.

The vertical incidence sections also image significant thicknesses of slope basin sediments, particularly to the northeast of OBS 13A (Fig. 3). The BSR is not commonly observed in these areas, but is most clearly seen in regions where other sediment reflectors are weak or absent at the level of the BSR. However, since the recent slope sediments are high amplitude and commonly parallel the seafloor, the BSR may still be present but obscured by stronger reflectors. In many locations, sediments are clearly imaged a short distance above a strong BSR (e.g., near SP 575 on Fig. 3A). That is, sediment "blanking" is not noted on the Cascadia Margin as it has been on the Blake Ridge (Shipley et al., 1979; Katzman et al., 1994; Lee et al., 1993).

Examples of data recorded on the OBSs are shown in Figures 5 and 6 . The effect of the simple processing applied is illustrated on the section recorded on Line 7A by instrument $14 \mathrm{~A}$, which is denoted by OBS 14-7A. Shot-receiver distances were calculated from the direct arrival, and the section was plotted at a reducing velocity of $2 \mathrm{~km} / \mathrm{s}$ (Fig. 5A). However, it is difficult to see near-offset events, especially because of the prominent bubble pulses at a period of $100 \mathrm{~ms}$. But when the section is flattened on the direct arrival, the BSR and several events above the BSR are seen as continuous events through zerooffset (Fig. 5B). Mixed results were achieved in the application of deconvolution in an attempt to remove the bubble pulses. Predictive deconvolution was unsuccessful in all cases, because it added noise which lead to significant deterioration in the quality of the BSR; that is, the assumptions used in statistical deconvolution break down be- 

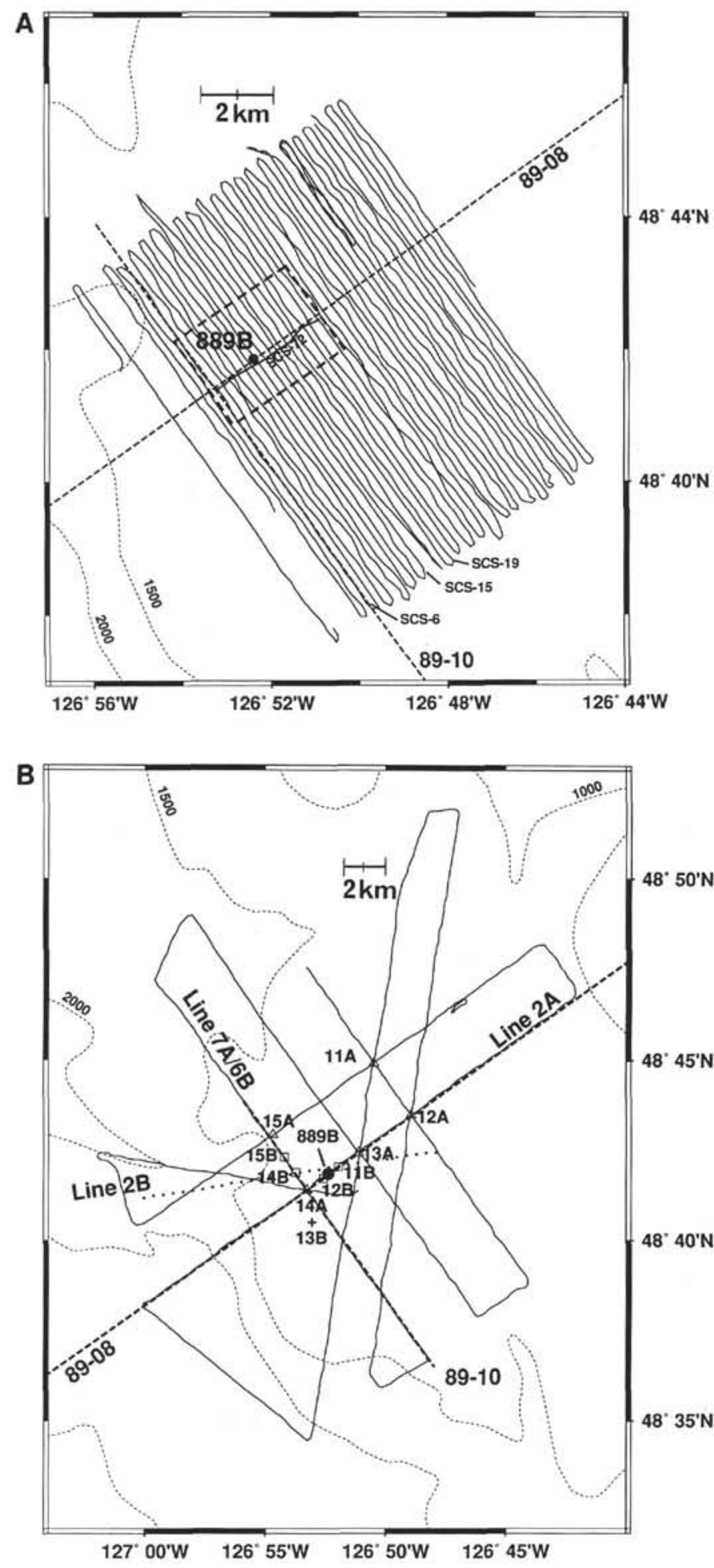

Figure 2. A. Location of tracks of single-channel seismic lines collected with a 120 -in. ${ }^{3}$ air gun source. The nominal grid spacing is $200 \mathrm{~m}$. The dashed box shows the area covered by another detailed grid of single-channel lines, at a nominal grid spacing of $100 \mathrm{~m}$, acquired with a 40-in. ${ }^{3}$ air gun. Lines 89-08 and $89-10$ are previously recorded multichannel seismic lines. B. Track lines during first deployment of the OBSs, which recorded a 120-in. ${ }^{3}$ air gun. Triangles indicate OBS locations for deployment A. Squares are OBS locations for deployment $\mathrm{B}$; Line $2 \mathrm{~B}$ is one of the 15 single-channel lines recorded during this deployment. cause the amplitude spectrum of the wide-angle data is not a good representation of the source amplitude spectrum. We were reasonably successful in using signature deconvolution on some data sets, where the source wavelet was derived by averaging $\sim 10$ of the nearest offset traces, keeping only the direct arrival pulse and the first two bubble pulses. Figure 5C shows a marked improvement in event definition and continuity for OBS 14-7A. We were moderately successful on other data sets, e.g. OBS 14-6B (Fig. 5D), where a strong remnant of the first bubble pulse still remains. Unsatisfactory results were obtained for a few data sets, such as OBS 11-2B (Fig. 5E), and only a simple filter with a low cut of $20 \mathrm{~Hz}$ was applied to suppress the $10-\mathrm{Hz}$ bubble frequency. However, the BSR was very clear on this record, and probably represents the strongest BSR arrival of the data set examined thus far.

A number of features were commonly consistent among the different OBS data sets. (1) The BSR was usually the strongest and most continuous event below the seafloor, and occurred at a zero-offset time of about $265 \mathrm{~ms}$ after the direct arrival. (2) The highest amplitudes occurred at a range of 2.4-3.6 km, where the BSR merges with direct arrival; in some cases these high-amplitude arrivals are aligned with the BSR at shorter offsets (e.g., Fig. 5E, east), whereas in others they appear to be slightly earlier (e.g., Fig. 5E, west). (3) A few reflectors could be identified above the BSR; the most consistent ones are denoted by R1 (about $80 \mathrm{~ms}$ after the direct arrival at zero-offset) and R2 (sporadically about 80-100 ms earlier than the BSR).

\section{TRAVELTIME INVERSION OF WIDE-ANGLE DATA Procedure}

An average velocity model was obtained along two lines. For Line $7 \mathrm{~A} / 6 \mathrm{~B}$, observed traveltimes were picked from the best phases on OBS 14A (Fig. 5C) and OBS 14B (Fig. 5D), plus OBS 13B and 15B (not shown). For Line $2 B$, observed times were picked from OBS $11 \mathrm{~B}$ (Fig. 5E). The modelling method used was the traveltime inversion scheme of Zelt and Smith (1992), in which layer velocities and the depth to layer boundaries could be varied so as to minimize the difference between observed and model traveltimes. A layer-stripping approach was utilized, in which model parameters for shallow layers were determined first, and then fixed for inversion of deeper layer parameters.

Three layers were modelled, not including the water layer. From the vertical-incidence seismic data along Line 7A/6B (Fig. 4), it was difficult to identify events that could be related unambiguously to wide-angle reflectors $\mathrm{R} 1$ and $\mathrm{R} 2 ; \mathrm{R} 1$ may correspond to a reflector within or at the base of the shallow slope basins, whereas R2 occurred within the accretionary wedge sediments where few vertical incidence reflections are seen. Because the layer thicknesses were very small, unreasonably large velocity variations were produced when both velocity and boundary depth were free parameters. Thus, for the first two layers below the seafloor, only layer thicknesses were allowed to vary. Velocities were fixed at values generally consistent with the trend of the Leg 146 well velocity information (MacKay et al., 1994), which provided velocities below about $60 \mathrm{mbsf}$ as determined from sonic logs and vertical seismic profiles (VSP). Velocities of 1.48 and $1.55 \mathrm{~km} / \mathrm{s}$ were chosen respectively for the top and base of Layer 1, whereas for Layer 2 velocities were assumed to range from $1.6 \mathrm{~km} / \mathrm{s}$ at the top to $1.7 \mathrm{~km} / \mathrm{s}$ at the base. In addition, the depth of the BSR was very well known from the drilling results ( $224 \mathrm{mbsf}$ ), and the BSR was parallel to the seafloor throughout the region. Thus, the BSR depth was fixed in the modelling procedure, and an inversion was performed to determine the average velocity of Layer 3 immediately above the BSR.

In Figure 6 we show ray path diagrams and traveltime fits corresponding to the inversion for Layer 1 thickness and Layer 3 velocity. For each of the layer inversions, RMS traveltime residuals were 


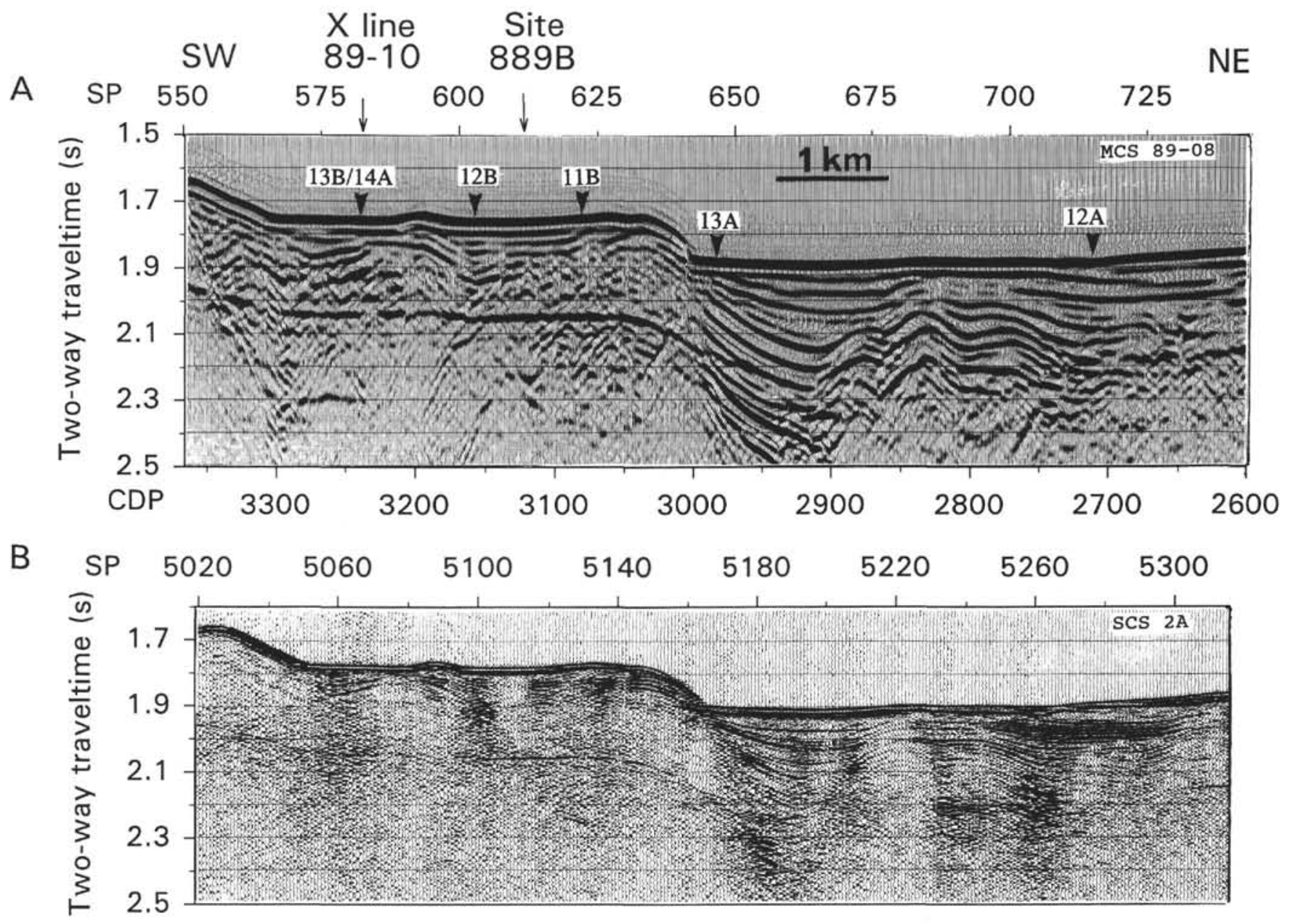

Figure 3. A. Multichannel seismic section along Line $89-08$, plotted with negative polarity so the BSR is primarily a positive-going pulse. The BSR is located 265-270 ms below the negative-going seafloor reflection. Locations are indicated for the ocean bottom seismometers that recorded a 120 -in. ${ }^{3}$ air gun. B. Singlechannel seismic section along Line $2 \mathrm{~A}$, which coincides with multichannel Line $89-08$. Plotting polarity is negative.

smaller than the estimated traveltime picking errors $(\sim 10 \mathrm{~ms})$. Final RMS values were $5 \mathrm{~ms}$ for Layer 1 thickness, $6 \mathrm{~ms}$ for Layer 2 thickness, and $10 \mathrm{~ms}$ for the velocity of Layer 3 .

The velocity gradient in Layer 3 above the BSR, which was fixed in the inversions above, could be estimated from the observation that the BSR was truncated at offsets of about $3.2-3.6 \mathrm{~km}$. It was assumed that the reflection was truncated at the offset corresponding to the ray that grazed the base of the layer, and that higher gradients would move this ray to smaller offsets. The velocity gradient consistent with the maximum observed offset was approximately $1.0 \mathrm{~km} / \mathrm{s} / \mathrm{km}$. For gradients of $0.5 \mathrm{~km} / \mathrm{s} / \mathrm{km}$, the BSR typically extended as far as 3.9 $\mathrm{km}$.

\section{Results}

The final velocity model along Line 7A/6B is shown in Figure 7. For Layer 1 (velocity $1.48-1.55 \mathrm{~km} / \mathrm{s}$ ), the thickness varied from 30 to $60 \mathrm{~m}$, and some correspondence is seen with the shallow reflectivity of the recent slope sediments imaged on the vertical incidence section (Fig. 4). The thickness of Layer 2 (velocity $1.6-1.7 \mathrm{~km} / \mathrm{s}$ ), which was poorly constrained because of the limited number of observations, varied from 60 to $120 \mathrm{~m}$.

The primary result from the traveltime inversion procedure is an estimate of the average velocity for Layer 3 above the BSR. Just northwest of OBS 15B, the velocity increased from $1.74 \mathrm{~km} / \mathrm{s}$ at the top of Layer 3 to $1.83 \mathrm{~km} / \mathrm{s}$ at the base, for an average velocity of 1.78 $\mathrm{km} / \mathrm{s}$ (Fig. 7); southeast of OBS $14 \mathrm{~A} / 13 \mathrm{~B}$, the velocity increased from 1.66 to $1.75 \mathrm{~km} / \mathrm{s}$, for an average of $1.70 \mathrm{~km} / \mathrm{s}$. In Figure 8 , velocity-depth profiles are shown for Line $2 \mathrm{~B}$ and for two locations along Line $7 \mathrm{~A} / 6 \mathrm{~B}$, together with VSP velocities and the sonic velocities from Hole 889B (MacKay et al., 1994). The OBS velocities are in very good agreement with the other velocity measurements.

Some indirect constraints are available from the wide-angle OBS data on velocities beneath the BSR at depths of up to several kilometers. No refractions corresponding to turning rays at this depth range are seen out to the maximum recorded offsets of 10-12 km. Simple ray trace modelling and synthetic seismogram calculations predict that significant amplitudes should be observed at ranges of approximately 6-7 km, for velocities increasing with depth according to expected sediment compaction profiles (e.g., $3.5 \mathrm{~km} / \mathrm{s}$ at $4 \mathrm{~km}$ depth, as observed by Yuan et al. (1994) on the Vancouver Island lower continental slope). To eliminate these amplitudes, a large low-velocity zone may be present below the BSR; a shadow zone is produced if velocities near $4 \mathrm{~km}$ depth are not larger than the maximum velocity above the BSR. However, alternative explanations still need to be investigated quantitatively; for example, attenuation in the accretionary wedge sediments may be much larger than expected for the high frequencies produced by the small air guns. 
A

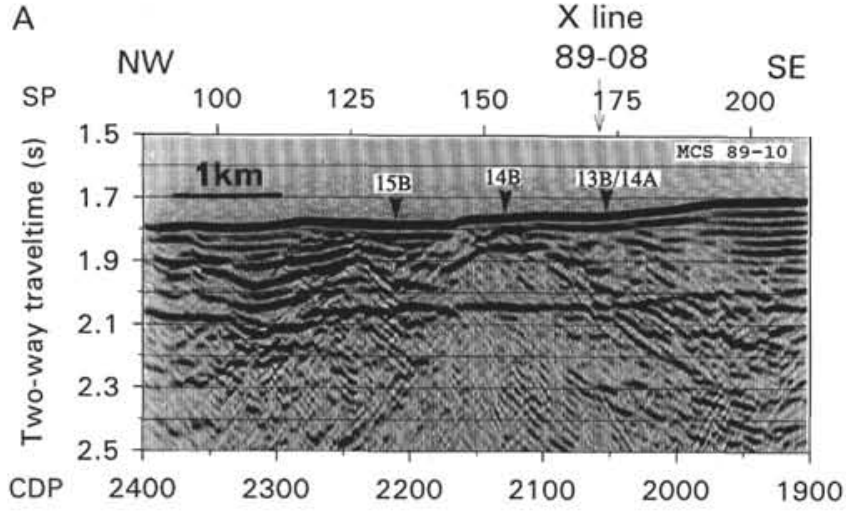

B

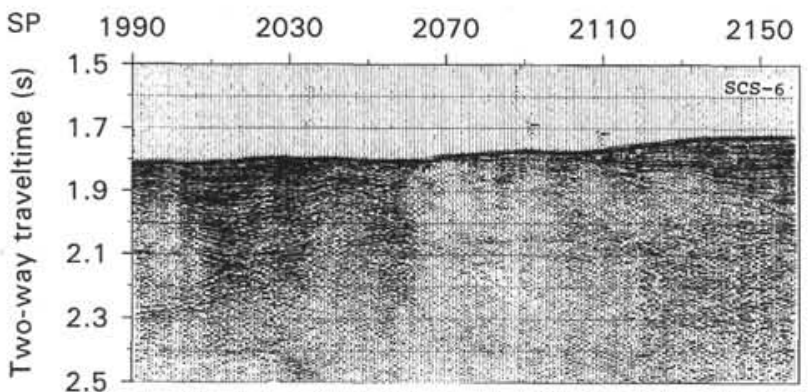

Figure 4. A. Multichannel seismic section along Line 89-10. Locations of ocean bottom seismometers are indicated. Plotting polarity is negative. B. Single-channel seismic section along Line SCS-6, which coincides with Line 89-10. Plotting polarity is negative.

\section{REFLECTION COEFFICIENTS AND BSR CONTINUITY}

The detailed grids of SCS lines collected near Hole 889 provide the opportunity to examine the detailed variation in BSR reflection strength and continuity, and thus to determine how representative the drill hole results are for this localized region. In addition, the possible frequency dependence of BSR seismic properties can be investigated, because recordings were made with both a 40 -in. ${ }^{3}$ air gun source and a 120 -in. ${ }^{3}$ source, which can be compared with previous multichannel seismic (MCS) results using a large 7820-in. ${ }^{3}$ air gun array. The dominant frequencies are approximately $150 \mathrm{~Hz}$ for the 40 -in. ${ }^{3}$ air gun, 75 $\mathrm{Hz}$ for the 120 -in. ${ }^{3}$ air gun, and $25 \mathrm{~Hz}$ for the large array, which corresponds to seismic wavelengths in water of 10,20 , and $60 \mathrm{~m}$.

\section{Calculation of Reflection Coefficients}

The reflection coefficients for the seafloor can be estimated from the relative amplitudes of the primary seafloor reflection and its first multiple. Following Anstey (1977) and Warner (1990), the reflection coefficient is $R_{s f}=G A_{n} / A_{p}$, where $A_{m}$ and $A_{p}$ are the recorded amplitudes for the multiple and primary. $G$ is the correction for geometrical spreading, which is assumed to be proportional to two-way traveltime; thus $G=2$ because the traveltime for the multiple is double that of the primary. Amplitudes for the seafloor reflection, the multiple, and the BSR were picked interactively from the SCS sections, for which processing was limited to bandpass filtering over the range 15$100 \mathrm{~Hz}$ for the 120 -in. ${ }^{3}$ air gun and $18-175 \mathrm{~Hz}$ for the 40 -in. ${ }^{3}$ air gun.
In Figure 9A the record section is shown for SCS-19 shot with the 120 -in. ${ }^{3}$ air gun (see Fig. 2A for location), which contains one of the strongest BSRs recorded in the single channel survey. Seafloor reflection coefficients are presented in Figure 9B. The average value for $R_{s f}$ is 0.16 , although values range along this and other lines from about 0.10 to 0.20 . These values are consistent with those from other deep-sea areas where BSRs are found, e.g., 0.13 on the Blake Ridge (Katzman et al., 1994) and 0.18 on the Peru margin (Miller et al., 1991). However, reflection coefficients are significantly higher $(0.20-0.30)$ along coincident multichannel seismic lines on the Vancouver Island margin, which used a large air gun array as a source (Hyndman and Spence, 1992). These higher reflection coefficients are possibly the result of significantly longer wavelengths for the air gun array, which sample deeper, and thus higher, velocities and densities below the seafloor.

The BSR reflection coefficients are estimated by comparison of the BSR amplitude $A_{B S R}$ to the primary seafloor amplitude $A_{p}$ (i.e., $\left.R_{B S R}=R_{s f} G A_{B S R} / A_{p}\right)$. Throughout the region, the two-way traveltimes for the seafloor and the BSR are approximately 1.8 and $2.1 \mathrm{~s}$, respectively, and so the spreading correction is $G=2.1 / 1.8$. Along Line SCS-19, the BSR reflection coefficient (Fig. 9C) averages about -0.06 , although in some areas excursions are up to -0.10 or more. This is significantly less than the reflection coefficient calculated for strong BSRs from the multichannel seismic data (Hyndman and Spence, 1992), where values of -0.10 to -0.15 were determined.

In Figure 10, BSR reflection coefficients are shown for two other SCS lines collected parallel to the continental margin with the 120in. ${ }^{3}$ air gun as a source. For SCS-15 (Fig. 10A), which passed within $200 \mathrm{~m}$ of Hole $889 \mathrm{~B}$, coefficients averaged -0.05 , which is slightly smaller than along SCS-19. To the southwest, or seaward, direction, Line SCS-6 (Fig. 10B), which coincides with multichannel Line 8910 , recorded much smaller reflection coefficients $(-0.02$ to -0.03$)$. On single-channel Line 2A, which was collected perpendicular to the margin with the 120 -in. ${ }^{3}$ air gun during the first deployment of OBSs, the BSR coefficients are on average about -0.05 (Fig. 11C), decreasing in localized regions to values of -0.02 or less (e.g., SP 5070 5090 , where the continuity on the seismic section of Fig. 3B is also much reduced).

BSR reflection coefficients were calculated for SCS-72, which recorded the higher frequency 40 -in. ${ }^{3}$ air gun. In comparing the record section for SCS-72 (Fig. 11A) with the nearly coincident portions of lines 89-08 and 2A (Fig. 3), we see a somewhat weaker and definitely less continuous BSR on the higher frequency line. In comparing the calculated reflection coefficients for SCS-72 and $2 \mathrm{~A}$, the average values for the 40 -in. ${ }^{3}$ air gun (about -0.04 ) are somewhat smaller than for the 120 -in. ${ }^{3}$ air gun. However, values decrease to less than -0.02 at the southwest end of SCS-72, and over the corresponding portion of Line $2 \mathrm{~A}$ there is also a indication of a trend to smaller values.

\section{BSR Distribution and Continuity}

From the grid of single-channel seismic lines recorded with the 120 -in. ${ }^{3}$ air gun, a map of BSR amplitudes was produced (Fig. 12B). Where a BSR could be identified, the amplitude of the event was picked interactively. The amplitudes varied significantly from lineto-line and from trace-to-trace within a line. To smooth these variations, an initial average was calculated over cells of approximate dimensions $185 \mathrm{~m}$ by $185 \mathrm{~m}$ (i.e., a cell width of about five shot intervals), and this was followed by a running average of each cell value with its eight nearest neighbors. A cell was then categorized as a strong reflector if the average value was larger than a threshold level $A_{l}$, or as a weak reflector if the average was less than $A_{l}$ but greater than a lower cutoff threshold $A_{2}$. Values for $A_{1}$ and $A_{2}$ were chosen by inspection and by subsequent trial-and-error adjustments. By comparison of the amplitudes along Line SCS-19 with the corresponding 
A

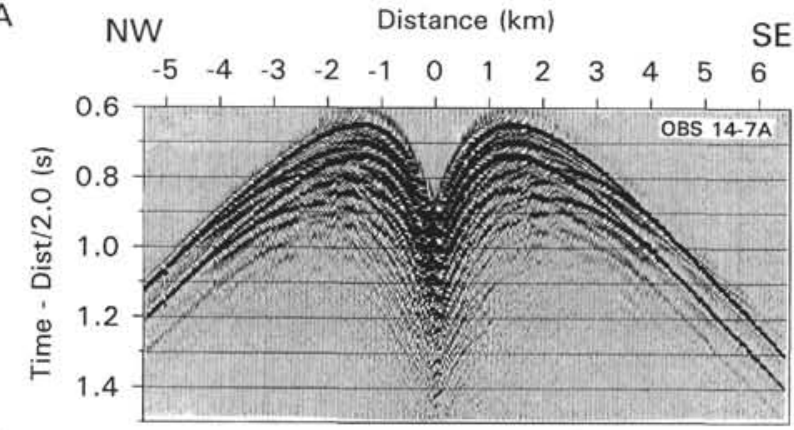

D
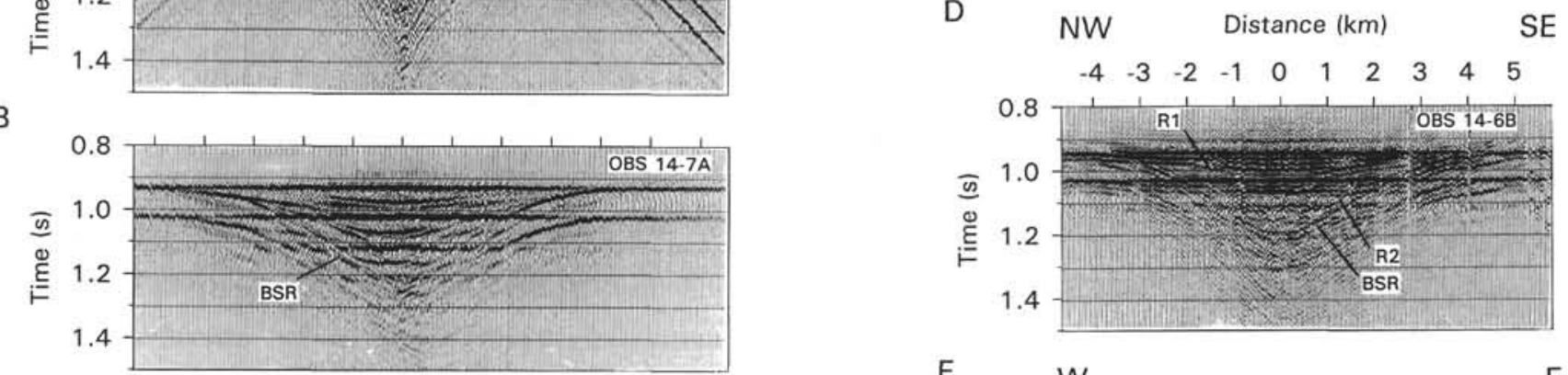

$E$
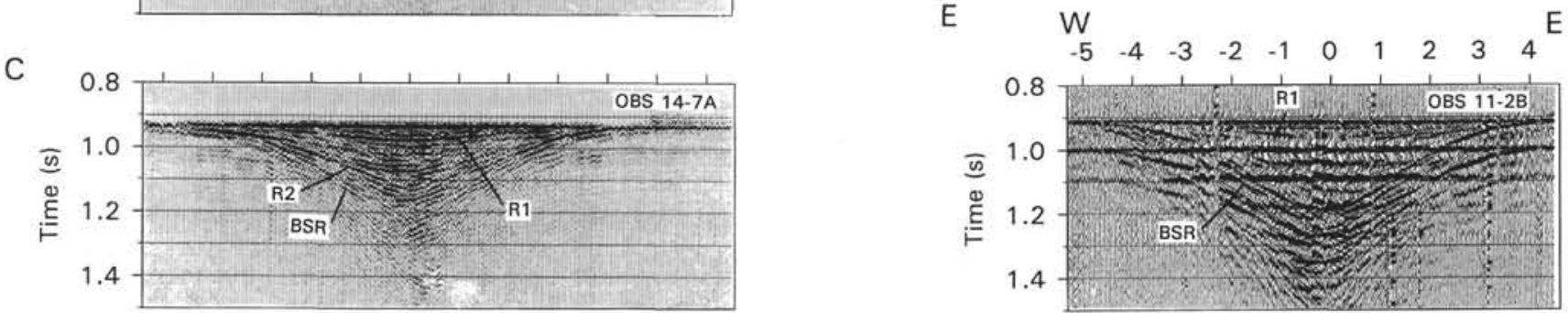

Figure 5. A. Wide-angle data recorded on OBS 14A Line 7A, plotted at a reduction velocity of $2.0 \mathrm{~km} / \mathrm{s}$. Plotting polarity is positive. B. Same data as in Figure $5 \mathrm{~A}$ except with static shifts applied to flatten the direct arrival. Plotting polarity is positive, so details can be seen in the negative-going BSR waveform. C. Same as Figure 5B but with signature deconvolution applied to remove the bubble pulses. Phases picked for traveltime inversion are R1, R2, and the BSR. Plotting polarity is positive. D. Wide-angle data recorded on OBS 14B Line 6B, flattened on the direct arrival. Signature deconvolution was applied to this data set with moderate success; strong remnants of the first bubble pulse remain. Plotting polarity is positive. E. Wide-angle data recorded on OBS 11A Line 2B. Deconvolution was unsuccessful on this data set, but the BSR is a very strong and easily picked event.

reflection coefficients calculated previously, the amplitude map can be calibrated approximately in terms of reflections coefficients: with the cutoff threshold $A_{2}$ set to $A_{l} / 5$, the upper threshold value $A_{/}$, which divides strong from weak reflectors, corresponds to a reflection coefficient of about -0.03 .

The SCS lines were also used to determine the detailed seafloor bathymetry (Fig. 12A), by interactively picking traveltimes of the seafloor reflection. The bathymetric contours are superimposed on the amplitude map (Fig. 12B), and a clear correlation is seen between BSR amplitudes and topography. In general, the strongest and most continuous BSR in the survey area is found beneath the topographic high to the southwest of Hole 889B. The maximum relief of this feature is actually quite small (e.g., see Line SCS-19 on Fig. 9A), only $\sim 250$ ms two-way traveltime or less than a 200 m elevation difference over a horizontal distance of about $2 \mathrm{~km}$, for a average slope of $5^{\circ}-$ $6^{\circ}$. Landward of the high, water depths increase abruptly where a slope basin of recent sediments is found, and the BSR is seen only sporadically in this area (e.g., to the northeast of SP 3000 on Line 8908 on Fig. 3A). However, the BSR strengthens in the northeast section of the map where the water depth decreases again (Figs. 3A, 3B, and $12 \mathrm{~B})$.

It should be noted that the BSR is correlated not only with a topographic high but also with a structural high. On MSC Line 89-10, the BSR cuts across stratigraphy and an anticlinal structure can be identified, centered on CDP 2125 (Fig. 4A). On parallel SCS lines to the northeast, the anticline can be traced as it emerges from beneath the cover of onlapping recent slope sediments (e.g., Fig. 9A), forming the topographic high clearly observed in the bathymetry map (Fig. 12A).

\section{DISCUSSION}

\section{Estimates of Hydrate Saturation}

Results from traveltime inversion and ray trace modelling of wide-angle OBS data provided control on the average velocity and gradient of the layer above the BSR. As shown in Figure 8, velocities for the instrument closest to Hole $889 \mathrm{~B}$ (OBS 11B, Line 2B) increased from 1.72 to $1.81 \mathrm{~km} / \mathrm{s}$ in the $80 \mathrm{~m}$ interval above the BSR. The variability among different inverted velocity-depth profiles in Figure 8 may provide an indication of the uncertainty in the velocity determinations (i.e. $\pm 0.05 \mathrm{~km} / \mathrm{s}$ ). No direct control on velocities below the BSR is obtained from the OBS data. However, results from full waveform inversions (Singh et al., 1993) and from sonic and VSP measurements (MacKay et al., 1994) indicate a 30-m-thick low velocity layer below the BSR with a velocity of about $1.55 \mathrm{~km} / \mathrm{s}$.

The OBS results provide control for an estimate of the impedance contrast across the BSR. We assume that no change occurs in the sediment bulk density if water in the pore space is replaced either by a small quantity of gas or by moderate quantities of hydrate (which has a density of $\sim 930 \mathrm{~kg} / \mathrm{m}^{3}$ ). With impedance defined as the product of velocity times density, the percentage change in impedance is equal to the percentage change in velocity. For a velocity of $1.81 \mathrm{~km} / \mathrm{s}$ 
A

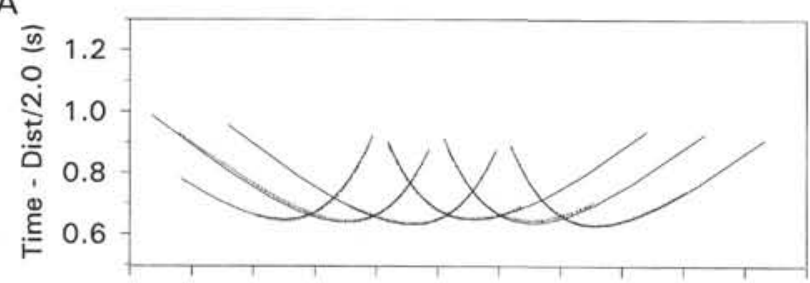

B

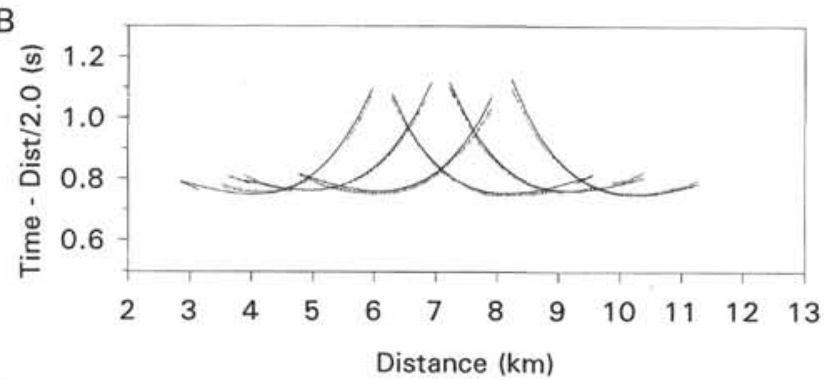

C

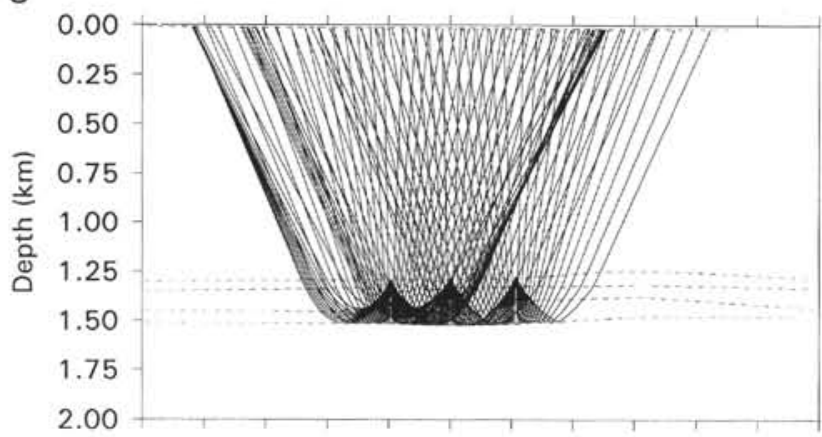

Figure 6. A. Observed (short vertical lines) and theoretical (solid lines) traveltimes resulting from the traveltime inversion for event $\mathrm{R} 1$, recorded on OBSs $15 \mathrm{~B}, 14 \mathrm{~B}$, and $13 \mathrm{~B} / 14 \mathrm{~A}$ along Line $7 \mathrm{~A} / 6 \mathrm{~B}$. B. Traveltime fit for the $\mathrm{BSR}$ along Line 7A/6B. C. Ray paths for the BSR reflection recorded on the three OBS sites.

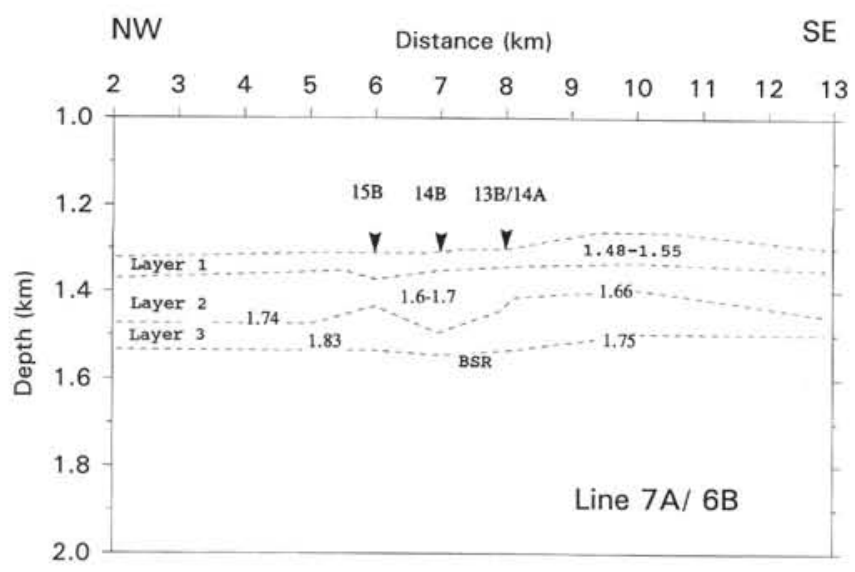

Figure 7. Final velocity model from the traveltime inversion. Velocities in the upper two layers are controlled by drill hole velocity information. Free parameters in the inversion are the depths to the base of Layer 1 and Layer 2 and the average velocity in Layer 3. Velocity nodes in Layer 3 were located at 5 and $9 \mathrm{~km}$ model distance.

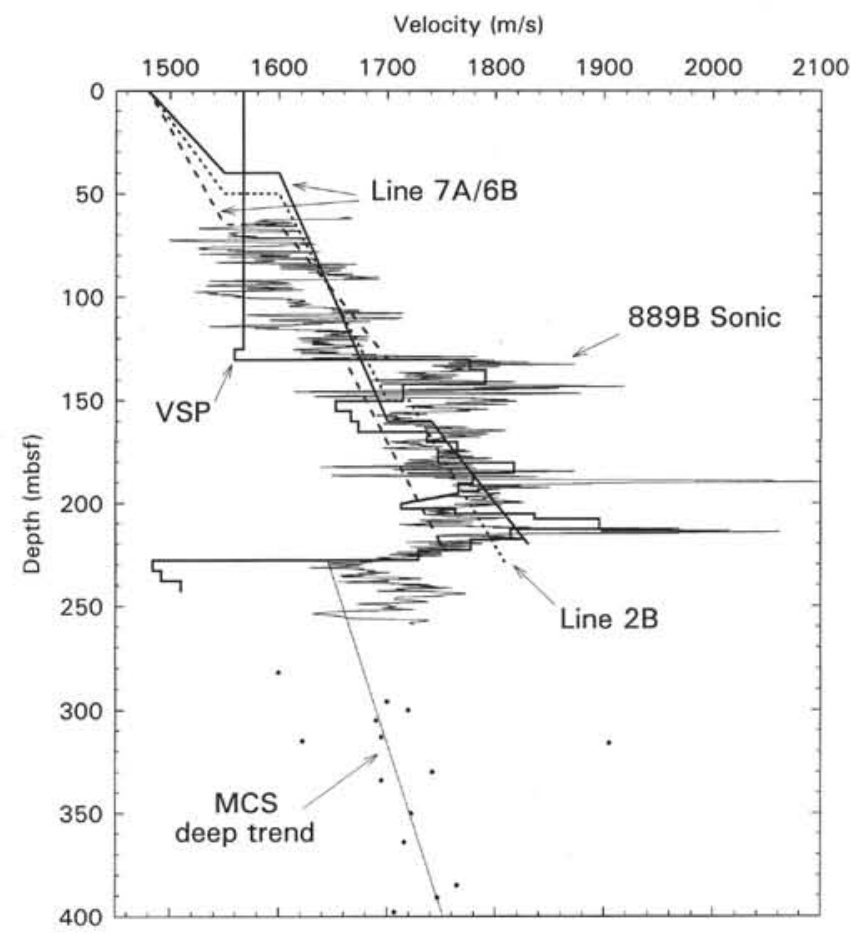

Figure 8. Velocity-depth profiles from the OBS traveltime inversions for Line $2 \mathrm{~B}$ (OBS 11B) and for two locations along Line 7A/6B (5 and $9 \mathrm{~km}$ model distance in Figure 7). Agreement is excellent with the vertical seismic profile (VSP) velocities and with the Hole 889B sonic log.

above the BSR and $1.55 \mathrm{~km} / \mathrm{s}$ below the BSR, then the impedance above the BSR is $17 \%$ higher than that below. This is equivalent to a BSR reflection coefficient of -0.08 , which compares reasonably well with the reflection coefficients calculated for a strong BSR on the SCS sections (e.g., Fig. 9C).

To estimate the amount of hydrate that may be present above the BSR requires comparison with impedances determined for unhydrated sediments. Few velocity estimates are available for the region below the BSR on the Cascadia Margin. Detailed multichannel velocity semblance analyses were conducted on Line 89-10 near Sites 889/ 890 (Yuan et al., 1994; Hyndman et al., 1994), and extrapolation of the deep velocity-depth trend upward to the BSR indicates velocities of about $1.65 \mathrm{~km} / \mathrm{s}$ (Fig. 8), which is a low value at this depth for oceanic sediments in general. The OBS velocity estimates are about 1.81 $\mathrm{km} / \mathrm{s}$ just above the BSR, or $1.77 \mathrm{~km} / \mathrm{s}$ in the 80 -m-thick interval above the BSR. These values correspond to an increase in velocity (and impedance) of $7 \%-10 \%$ due to the presence of hydrate.

To quantitatively estimate the amount of hydrate from the increase in velocity, we used two methods. The first was based on the semiquantitative relation of Hyndman et al. (1994) and Hyndman and Spence (1992), which assumes that the porosity reduction by infilling with hydrate has the same effect on velocity as the normal compaction porosity reduction with depth. From Figure 5 in Hyndman and Spence (1992), a 7\%-10\% increase in velocity corresponds to approximately $15 \%-20 \%$ of the pore spaces filled by hydrate; this assumes a sediment porosity of $50 \%$, consistent with drill core measurements for Hole $889 \mathrm{~B}$ in the $50-80 \mathrm{~m}$ interval above the BSR. In the second method, based on Minshull et al. (1994), velocities are interpolated between the velocity of fully hydrated sediments (calculated with the time-average relation) and the velocity for water-filled sediment. Here, the observed increase in impedance corresponds to a hydrate saturation of $11 \%-14 \%$. However, for both of these methods, 

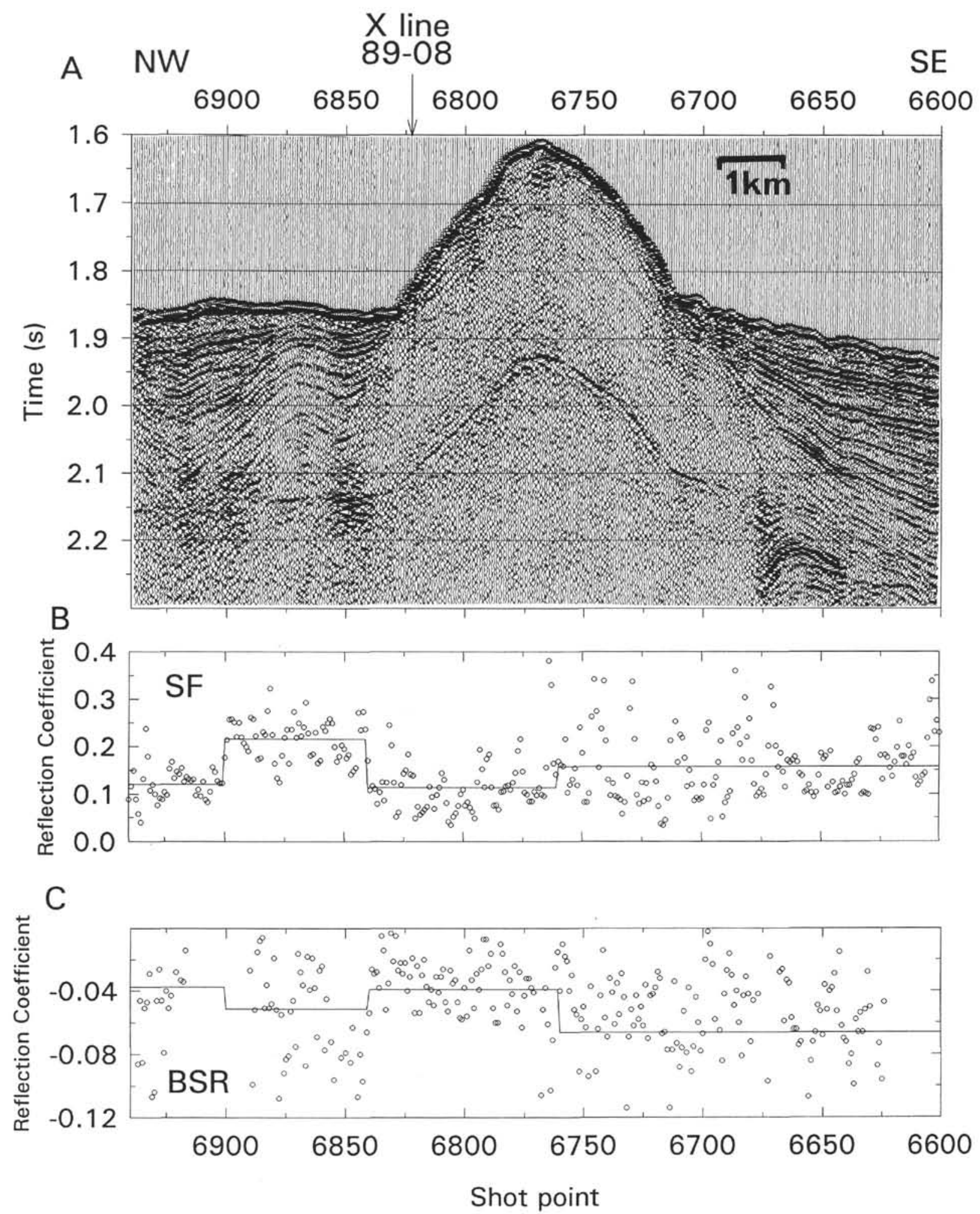

Figure 9. A. Single-channel seismic section recorded along SCS-19 with a 120-in. ${ }^{3}$ air gun as source. B. Seafloor reflection coefficients along SCS-19. The solid line represents the average reflection coefficient calculated over different segments of the profile. C. BSR reflection coefficients along SCS-19. 
an increase in the reference sediment velocity would give a lower inferred hydrate saturation.

\section{Lateral Variations in Reflection Strength}

The lateral variability in BSR reflection strength (Fig. 12B) may be due to variations in hydrate concentration or to variations in the amount of free gas beneath the hydrate. The most prominent region of strong BSR is a broad area of approximate dimensions $4 \mathrm{~km}$ by 7 $\mathrm{km}$, lying mostly to the southeast of the drill hole. Within this region, hydrate concentrations are likely comparable to those calculated above for the drill hole and OBS locations; that is, hydrate fills at most $10 \%-20 \%$ of the pore spaces. The strong BSR region appears to be correlated with a topographic and structural high. Correlation with topography has been observed by other authors (Katz, 1982; Dillon and Paull, 1983), and is consistent with migration of gas along the BSR due to buoyancy forces, assuming that the hydrated zone is less permeable than the sediments beneath the BSR. Correlation of high BSR amplitudes and low velocity gas zones with structural highs has been noted off Colombia by Minshull et al. (1994), who suggest that the structure would tend to focus migrating fluids or gas. In our map area on the Vancouver Island margin, we are not able to distinguish topographic from structural effects in providing the dominant control in the accumulation of hydrate or gas.

Outside of the central strong region of apparently continuous BSR, the distribution of hydrate and free gas is more sporadic. The strength of the BSR can change significantly along a seismic line and between lines, which are separated by only $200 \mathrm{~m}$. In areas of weak BSR, hydrate saturations are likely less than $10 \%$, but it is not possible to constrain hydrate or gas concentrations further without more precise velocity information. We hope that a planned tomographic inversion of the full OBS data set will provide such information and allow correlations with the BSR amplitude variations.

\section{BSR Variability with Different Frequency Sources}

The BSR is seen as a single reflector on all seismic sections, independent of whether the source is a large air gun array, with wavelengths of $\sim 60 \mathrm{~m}$, or a small single air gun, with wavelengths of $\sim 10$ $\mathrm{m}$. Where the same lines have been shot with different sources, we also observe that the reflection coefficients for the lower frequency source are as large or larger than those for the higher frequency source. We believe this provides some general constraints on velocity gradients in the transition regions between normal sediments, hydrated sediments, and gas-saturated sediments. In particular, it rules out models that contain thin layers with sharp tops and bottoms and that rely on interference between reflections from the two layer boundaries to produce a single reflected pulse. If both boundaries were sharp, then the layer thickness must be less than 2-3 m, the quarterwavelength of the 40 -in. ${ }^{3}$ air gun, or else the two boundaries could be resolved. But such a thin layer would result in very small BSR reflection coefficients for the long wavelengths of the bigger guns. In contrast, the actual observed reflection coefficients are larger for the big air gun source than for the smaller ones.

The most significant implication of this argument is that the hydrate or free gas beneath the hydrate cannot be concentrated in a several-meter-thick layer at the BSR. Thus, the BSR itself is produced by a reflection from a single interface, and the velocity transition at the interface must be very sharp to produce significant amplitudes for the small air gun source. Furthermore, the velocity transition at the top of the hydrate layer or base of the gas layer must be gradational so that it does not appear as a sharp interface for any of the sources. As well, the thickness of the hydrate layer is likely to be at least $15 \mathrm{~m}$ (the quarter-wavelength of the large air gun array), to produce the large reflection coefficients for the large array. To constrain velocity

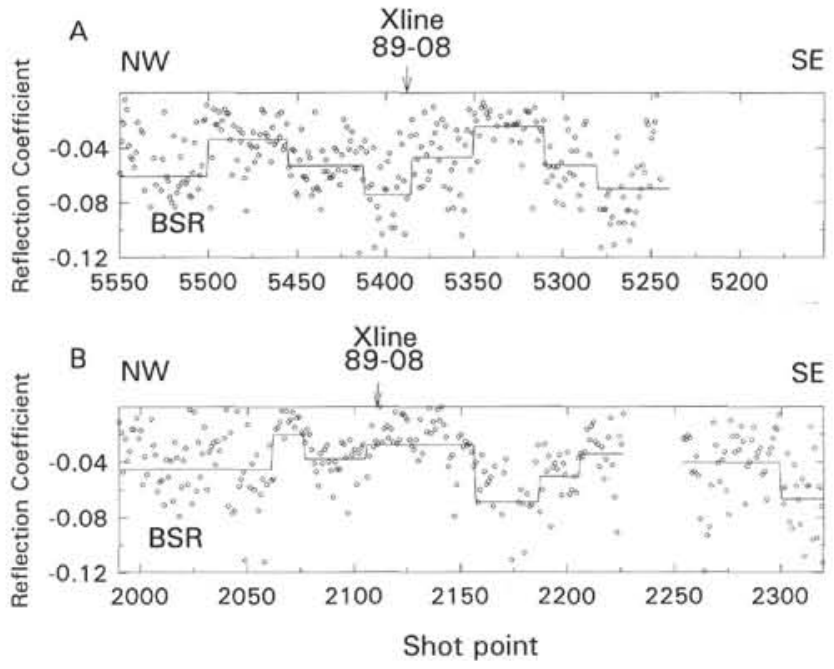

Figure 10. BSR reflection coefficients along (A) SCS-15 and (B) SCS-6, single-channel seismic lines recorded with a 120 -in. ${ }^{3}$ air gun. The solid line represents the average reflection coefficient calculated over different segments of the profile.

gradients more quantitatively, vertical-incidence synthetic seismogram modeling is required to address these frequency-dependent effects.

With the higher frequency source, the BSR appears to be less laterally continuous than with the lower frequency source (e.g., compare Figs. 3A, 3B, and $11 \mathrm{~A}$; or Figs. $4 \mathrm{~A}$ and $4 \mathrm{~B}$ ). Part of this difference may be due to the lower signal-to-noise ratio of the smaller, higher frequency source, such that signal is lost among noise and interference from other sources. The higher frequency signals may also be affected by small-scale lateral variations in structure, which produces frequency-dependent scattering. An additional factor may be the decrease in the size of the Fresnel zone with increasing frequency. The major contribution to the reflected signal strength comes from the first Fresnel zone, for which the diameter $w$ is given by $w=$ $(2 d l)^{1 / 2}$ (Sheriff and Geldart, 1982), where $l$ is the dominant wavelength and $d$ is the water depth (1.3 km near Hole 889B). The Fresnel zone diameters are 395,228 , and $161 \mathrm{~m}$ in width for the large air gun array, the 120 -in. ${ }^{3}$ air gun, and the 40 -in..$^{3}$ air gun, respectively. We speculate that the lower frequency sources appear to have a more continuous BSR because the BSR has gaps or reductions in strength over dimensions of approximately $200-400 \mathrm{~m}$. For the small source, the gaps will be better resolved and amplitudes over the gaps will be more significantly reduced.

\section{CONCLUSIONS}

The following conclusions from this study should be emphasized:

1. Traveltime analysis of wide-angle arrivals indicates that the average velocity in the $90( \pm 30) \mathrm{m}$ interval above the BSR varied from 1.70 to $1.78 \mathrm{~km} / \mathrm{s}$, and that velocity gradients were approximately $1.0 \mathrm{~km} / \mathrm{s} / \mathrm{km}$.

2. To explain the increased seismic velocity above a reference velocity of $1.65 \mathrm{~km} / \mathrm{s}$, we estimate that $11 \%-20 \%$ of the pore space above the BSR is filled by hydrate.

3. A single BSR reflector is seen on seismic sections with significantly different source frequencies, and the lowest frequency source produces the largest BSR reflections. Therefore, hy- 
drate or free-gas is unlikely to be concentrated in a severalmeter-thick layer at the BSR.

4. The strongest BSR occurs beneath a ridge formed by an anticlinal uplift of accretionary wedge sediments. Drill Hole $889 \mathrm{~B}$ is located on the northwest flank of this ridge, in an area of strong BSR but only a few hundred meters from regions where the BSR weakens significantly.

5. The hydrate may be distributed laterally in a discontinuous or disseminated layer, with a scale of variation of approximately 200-400 m. Gaps in the BSR are most evident on seismic sections recorded with the smallest air gun size, with lateral resolution given by a Fresnel zone diameter of $<200 \mathrm{~m}$.

\section{ACKNOWLEDGMENTS}

We thank Graham Westbrook, Nathan Bangs, and Roland von Huene for their helpful recommendations and useful reviews of the paper. The paper also benefitted from discussions from Roy Hyndman. GDS was supported by NSERC research grant OGP0156159. TAM was supported by NERC grant GR9/1048. This is University of Cambridge, Department of Earth Sciences contribution 4178.

\section{REFERENCES}

Anstey, N.A., 1977. Seismic Interpretation: The Physical Aspects: Boston (Int. Human Rights Dev. Corp.)

Dillon, W.P., and Paull, C.K., 1983. Marine gas hydrates, II. Geophysical evidence. In Cox, J.L. (Ed.), Natural Gas Hydrates: Properties, Occurrences, and Recovery: Stoneham, MA (Butterworths), 73-90.

Domenico, S.N., 1976. Effect of brine-gas mixture on velocity in an unconsolidated sand reservoir. Geophysics, 41:882-894.

Englezos, P., and Bishnoi, P.R., 1988. Predictions of gas hydrate formation conditions in aqueous solutions. Am. Inst. Chem. Eng., 34:1718-1721.

Hyndman, R.D., and Spence, G.D., 1992. A seismic study of methane hydrate marine bottom simulating reflectors. J. Geophys. Res., 97:66836698.

Hyndman, R.D., Spence, G.D., Yuan, T., and Davis, E.E., 1994. Regional geophysics and structural framework of the Vancouver Island margin accretionary prism. In Westbrook, G.K., Carson, B., Musgrave, R.J., et al., Proc. ODP, Init. Repts., 146 (Pt. 1): College Station, TX (Ocean Drilling Program), 399-419.

Katz, H.R., 1982. Evidence of gas hydrates beneath the continental slope, east coast, North Island, New Zealand. N. Z. J. Geol. Geophys., 25:193199.

Katzman, R., Holbrook, W.S., and Paull, C.K., 1994. A combined verticalincidence and wide-angle seismic study of a gas hydrate zone, Blake Ridge. J. Geophys. Res., 99:17975-17995.

Kvenvolden, K.A., 1993. Gas hydrates: geological perspective and global change. Rev, Geophys., 31:173-187.

Kvenvolden, K.A., Claypool, G.E., Threlkeld, C.N., and Sloan, E.D., 1984 Geochemistry of a naturally occurring massive marine gas hydrate. Org. Geochem., 6:703-713.
Lee, M.W., Hutchinson, D.R., Dillon, W.P., Miller, J.J., Agena, W.F., and Swift, B.A., 1993. Method of estimating the amount of in situ gas hydrates in deep marine sediments. Mar. Pet. Geol., 10:493-506.

MacDonald, G.J., 1990. Role of methane clathrates in past and future climates. Clim. Change, 16:247-281.

MacKay, M.E., Jarrard, R.D., Westbrook, G.K., and Hyndman, R.D., 1994 Origin of bottom-simulating reflectors: geophysical evidence from the Cascadia accretionary prism. Geology, 22:459-462.

Miller, J.J., von Huene, R., and Lee, M.W., 1991. An analysis of a seismic reflection from the base of a gas hydrate zone, offshore Peru. AAPG Bull., 75:910-924.

Minshull, T.A., Singh, S.C., and Westbrook, G.K., 1994. Seismic velocity structure at a gas hydrate reflector, offshore western Colombia, from full waveform inversion. J. Geophys. Res., 94:7387-7402.

Minshull, T.A., and White, R., 1989. Sediment compaction and fluid migration in the Makran accretionary prism. J. Geophys. Res., 94:7387-7402.

Murphy, W.F., III, 1984. Acoustic measures of partial gas saturation in tight sandstones. J. Geophys. Res., 89:11549-11559.

Sheriff, R.E., and Geldart, L.P., 1982. Exploration Seismology (Vol. 1): History, Theory, and Data Acquisition: Cambridge (Cambridge Univ. Press).

Shipley, T.H., Houston, M.H., Buffler, R.T., Shaub, F.J., McMillen, K.J., Ladd, J.W., and Worzel, J.L., 1979. Seismic evidence for widespread possible gas hydrate horizons on continental slopes and rises. AAPG Bull., 63:2204-2213.

Singh, S.C., and Minshull, T.A., 1994. Velocity structure of a gas hydrate reflector at Ocean Drilling Program site 889 from a global seismic waveform inversion, J. Geophys. Res., 99:24221-24233.

Singh, S.C., Minshull, T.A., and Spence, G.D., 1993. Velocity structure of a gas hydrate reflector. Science, 260:204-207.

Sloan, E.D., 1990. Clathrate Hydrates of Natural Gasses: New York (Marcel Dekker).

Spence, G.D., Hyndman, R.D., Davis, E.E., and Yorath, C.J., 1991. Seismic structure of the northern Cascadia accretionary prism: evidence from new multichannel seismic reflection data. In Meissner, R.O., Brown, L.D., Duerbaum, H.-J., Franke, W., Fuchs, K., and Seifert, F. (Eds.), Continental Lithosphere: Deep Seismic Reflections. Am. Geophys. Union, Geodyn. Ser., 22:257-263.

Warner, M.R., 1990. Absolute reflection coefficients from deep seismic reflections. Tectonophysics, 173:15-23.

Wood, W.T., and Stoffa, P.L., 1994. Quantitative detection of methane through high-resolution seismic velocity analysis. J. Geophys. Res., 99:9681-9695.

Yuan, T., Spence, G.D., and Hyndman, R.D., 1994. Seismic velocities and inferred porosities in the accretionary wedge sediments at the Cascadia Margin. J. Geophys. Res., 99:4413-4427.

Zelt, C.A., and Smith, R.B., 1992. Seismic traveltime inversion for 2-D crustal velocity structure. Geophys. J. Int., 108:16-34.

Date of initial receipt: 6 September 1994

Date of acceptance: 23 February 1995

Ms 146SR-228 


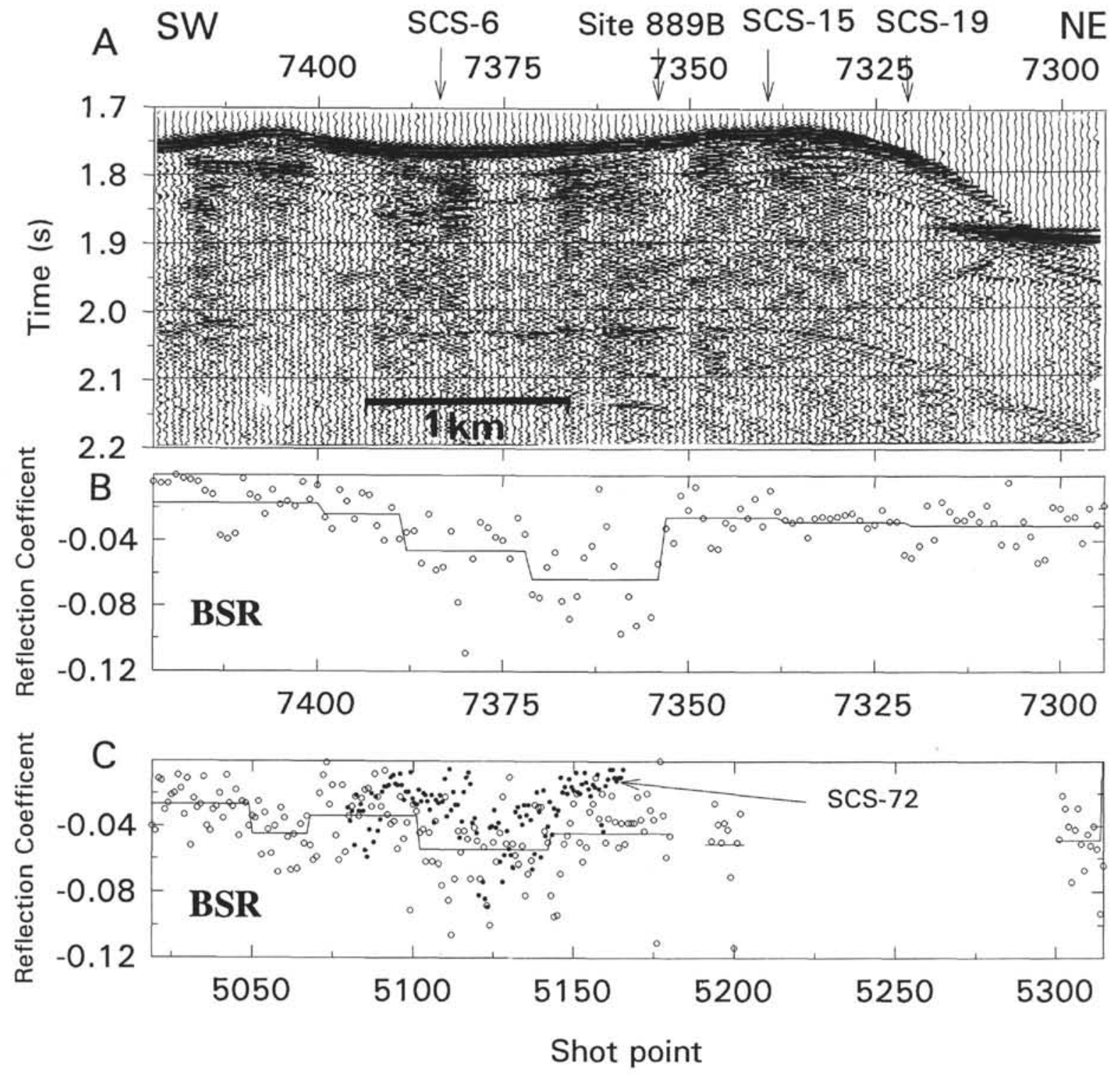

Figure 11. A. Single-channel seismic section recorded along SCS-72 with a 40 -in. ${ }^{3}$ air gun as source. This line is nearly coincident with a portion of multichannel Line 89-10 and single-channel Line 2A (Fig. 4). B. BSR reflection coefficients along SCS-72. The solid line represents the average reflection coefficient calculated over different segments of the profile. C. BSR reflection coefficients along Line $2 \mathrm{~A}$, recorded with a 120 -in. ${ }^{3}$ air gun, are indicated by open circles. Reflection coefficients for SCS-72 (from Fig. 11B), which is coincident with a portion of Line 2A, are indicated by solid circles. 


\section{A}
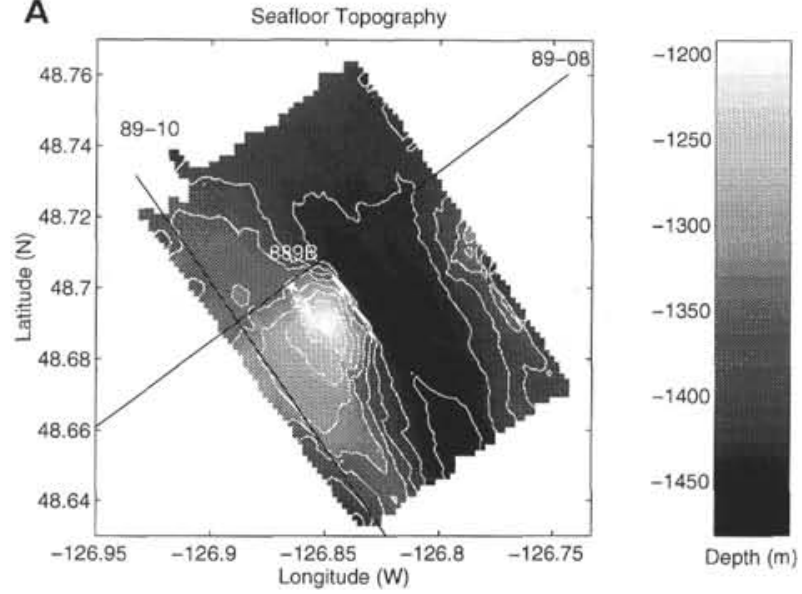

B Bottom Simulating Reflector Amplitude

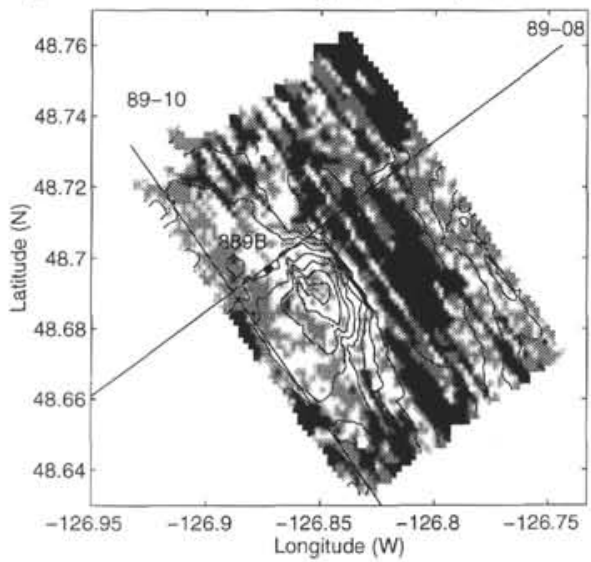

Strong Reflector

Weak Reflector

No Reflector

Figure 12. A. Map of seafloor bathymetry determined from traveltimes picked from the grid of single-channel seismic lines (Fig. 2A) acquired with a 120-in. ${ }^{3}$ air gun source. Note the topographic high to the southeast of Hole 889B. A recent sediment slope basin lies to the northeast of the high. B. Amplitude distribution for the BSR, with the 120 -in. ${ }^{3}$ air gun as the source. The amplitude threshold $A_{1}$ between strong and weak reflections corresponds to a reflection coefficient of approximately -0.03 . Black regions are areas where no BSR was seen or where the amplitude fell below a lower threshold $A_{2}=A_{l} / 5$. Seafloor bathymetry contours from Figure 12A are superimposed on the amplitude map. 